\title{
Influence of Alleviating Hangover and Protecting Liver Granules of Flower of Pueraria lobata and Ginseng Radix et Rhizoma on Acute Alcoholic Liver Disease of Mice
}

\author{
Min Yang, Dan Zhang \\ College of Traditional Chinese Medicine, Jilin Agricultural Science and Technology University, Jilin, 132001, \\ China
}

Keywords: Flower of Pueraria lobata, Ginseng Radix et Rhizoma, Granules, Acute alcoholic liver disease, Liver index, ALT, AST

\begin{abstract}
To study the protective effect of Pueraria ginseng and sobering up liver protecting Granule on acute alcoholic liver injury in mice. 60 Kunming class SPF mice were randomly divided into blank control group, alcohol model group, liver protecting tablet group, kudzu flower ginseng, sobering up liver protection granule (low, middle, high) dose group. By data analysis, it can be concluded that Radix Pueraria ginseng and sobering up liver protecting granules have different therapeutic and protective effects on acute alcoholic liver injury in mice, among which the effect of high dose group is more remarkable.
\end{abstract}

\section{Materials and Methods}

Materials. SPF class Kunming mice were only $60(18+22)$ g, purchased in Changchun medical animal experimental center. The feeding temperature was kept at $20 \sim 25$ DEG C, and the mice were free to drink water and feed. Pueraria hangover ginseng Hugan granule (Agriculture Science And Technology College laboratory preparation); 95\% ethanol (Agriculture Science And Technology College, made of 50\% ethanol; huganpian (standby) Heilongjiang sunflower pharmaceutical Limited by Share Ltd, production batch number: Zhunzi Z20003336); 0.9\% ns (Hangzhou Minsheng Pharmaceutical Co. Ltd., batch H33021575); aspartate aminotransferase (AST) kit (Nanjing Jiancheng Biological Engineering Institute, production batch number: 20161101); alanine aminotransferase (ALT) ELISA Kit (Nanjing Jiancheng Biological Engineering Institute, production batch number: 20161103); all kit were stored at 4 - 8 DEG C.

Methods. 60 mice were randomly divided into 6 groups, 10 rats in each group were divided into control group (A), alcohol model group (B) and huganpian group (C), Pueraria ginseng hangover Hugan granule low dose group (D), Ge Hua ginseng hangover dose group in Hugan granules (E), Ge ginseng flower hangover liver protection particles in high dose group (F). According to pharmacopoeia records, Ge Hua day dose of $10 \sim 15 \mathrm{~g}$, ginseng daily dose is $3 \sim 9 \mathrm{~g}$, the preparation of clinical prescription taking crude drug for flower $10 \mathrm{~g}$, Ge ginseng 5g, 15g, in human drug safety range. The dosage of this granule contains extract 3.5G, and is made from 1:4 ratio of extract and filling agent. Therefore, the recommended dose is $17.5 \mathrm{~g} / \mathrm{d}$. According to the conversion ratio of experimental animal to body surface equivalent volume. The low dose group is $1.1375 \mathrm{~g} / \mathrm{kg}$, middle dose group $2.275 \mathrm{~g} / \mathrm{kg}$, high dose group is $4.550 \mathrm{~g} / \mathrm{kg}$. The dosage of liver protecting tablet group was adjusted according to the drug instruction, and the dosage of the mice was $0.7 \mathrm{~g} / \mathrm{kg}$.

Every weekend the rats were weighed at the end of the 4 week (20d) after the last administration, weighing, record the weight, after the last administration, all mice were in at 8 p.m. the day before fasting, fasting $16 \mathrm{~h}$, water the next day by chloral hydrate, blood from the abdominal aorta after removal of the liver, physiological salt after cleaned, and then dry with filter paper, that weighed the 
liver, calculate the liver index. All rats were anesthetized with chloral hydrate at the end of the 4 week (20d) and the abdominal aorta was removed. Fresh blood was taken, and serum was separated by high-speed refrigerated centrifuge $3000 \mathrm{r} / \mathrm{min}$ and centrifuged $10 \mathrm{~min}$. The activity of serum ALT and AST was measured by a semi-automatic biochemical analyzer. According to the reagent kit manual operation, the serum and reagents required mixing, room temperature placed $1 \mathrm{~min}$, in the $520 \mathrm{~nm}$ wave advantage, with blank tube zero, read the value.

Using SPSS22.0 statistical software, the experimental data were statistically analyzed, and the data were expressed by mean + standard deviation. $(\mathrm{P}<0.05)$ the difference was statistically significant.

\section{Results and Analysis}

Determination Result of Standard Curve. The absorbance of ALT measured by spectrophotometer is shown in Table 1.

Table 1. Determination result of ALT standard curve

\begin{tabular}{cccccc}
\hline & $\mathbf{0}$ & 1 & 2 & 3 & 4 \\
\hline $\begin{array}{c}\text { Absorbance value in the } \\
\text { experiment }\end{array}$ & 0.215 & 0.304 & 0.371 & 0.457 & 0.554 \\
$\begin{array}{c}\text { Absolute absorbance value in the } \\
\text { experiment }\end{array}$ & 0 & 0.089 & 0.156 & 0.242 & 0.339 \\
$\begin{array}{c}\text { Equivalent to the Carmen unit of } \\
\text { enzyme activity }\end{array}$ & 0 & 28 & 57 & 97 & 150 \\
\hline
\end{tabular}

The absorbance of AST measured by spectrophotometer is shown in Table 2.

Table 2. Determination result of AST standard curve

\begin{tabular}{cccccc}
\hline & $\mathbf{0}$ & 1 & 2 & 3 & 4 \\
\hline $\begin{array}{c}\text { Absorbance value in the } \\
\text { experiment }\end{array}$ & 0.256 & 0.349 & 0.449 & 0.565 & 0.677 \\
$\begin{array}{c}\text { Absolute absorbance value in the } \\
\text { experiment }\end{array}$ & 0 & 0.093 & 0.193 & 0.309 & 0.421 \\
$\begin{array}{c}\text { Equivalent to the Carmen unit of } \\
\text { enzyme activity }\end{array}$ & 0 & 24 & 61 & 114 & 190 \\
\hline
\end{tabular}




\section{Influence on Weight of Mice of Alleviating Hangover and Protecting Liver Granules of Flower of Pueraria lobata and Ginseng Radix et Rhizoma.}

Table 3. Influence on Weight of Mice $(\bar{X} \pm s$, Micennumbern $=10)$

\begin{tabular}{ccccc}
\hline Different groups & Dose(g/kg) & $\begin{array}{c}\text { Initial } \\
\text { weight/g }\end{array}$ & Final weight/g & $\begin{array}{c}\text { Increased } \\
\text { weight/g }\end{array}$ \\
\hline Control group (A) & -- & $22.18 \pm 3.68$ & $28.97 \pm 3.83$ & $6.79 \pm 2.7$ \\
Alcohol model group (B) & -- & $20.60 \pm 4.22$ & $27.57 \pm 4.62$ & $6.97 \pm 3.6$ \\
Protecting Liver Group (C) & $0.7 \mathrm{~g} / \mathrm{kg}$ & $23.22 \pm 1.39$ & $30.17 \pm 3.12$ & $6.95 \pm 3.4$ \\
Low dose group (D) & $1.1375 \mathrm{~g} / \mathrm{kg}$ & $21.33 \pm 4.32$ & $28.19 \pm 4.97$ & $6.86 \pm 2.1$ \\
Middle dose group (E) & $2.275 \mathrm{~g} / \mathrm{kg}$ & $21.73 \pm 3.93$ & $28.70 \pm 4.45$ & $6.97 \pm 2.4$ \\
High dose group (F) & $4.550 \mathrm{~g} / \mathrm{kg}$ & $22.60 \pm 3.09$ & $29.52 \pm 2.35$ & $6.92 \pm 3.1$
\end{tabular}

Note: Compared with A group: ${ }^{\mathrm{a}} \mathrm{P}<0.05{ }^{\mathrm{b}} \mathrm{P}<0.01$; Compared with $\mathrm{B}$ group: ${ }^{\mathrm{C}} \mathrm{P}<0.05{ }^{\mathrm{d}} \mathrm{P}<0.01$; Compared with c group: ${ }^{\mathrm{e}} \mathrm{P}<0.05{ }^{\mathrm{f}} \mathrm{P}<0.01$.

As can be seen, after 20d, compared with the initial weight, the weight of mice increased. However, statistical analysis $(\mathrm{P}>0.05)$ showed no significant difference between the two groups. It showed that the effect of liver clearing granules on the weight of mice was not obvious.

Influence on Liver Index of Mice of Alleviating Hangover and Protecting Liver Granules of Flower of Pueraria lobata and Ginseng Radix et Rhizoma.

Table 4. Influence on liver index of Mice $(\bar{x} \pm s$, Mice nnumbern $=10)$

\begin{tabular}{ccccc}
\hline Different groups & Dose(g/kg) & $\begin{array}{c}\text { Initial } \\
\text { weight/g }\end{array}$ & Final weight/g & $\begin{array}{c}\text { Liver index } \\
(\%)\end{array}$ \\
\hline Control group (A) & -- & $22.18 \pm 3.68$ & $28.97 \pm 3.83$ & $6.79 \pm 2.7$ \\
Alcohol model group (B) & -- & $20.60 \pm 4.22$ & $27.57 \pm 4.62$ & $6.97 \pm 3.6$ \\
Protecting Liver Group (C) & $0.7 \mathrm{~g} / \mathrm{kg}$ & $23.22 \pm 1.39$ & $30.17 \pm 3.12$ & $6.95 \pm 3.4$ \\
Low dose group (D) & $1.1375 \mathrm{~g} / \mathrm{kg}$ & $21.33 \pm 4.32$ & $28.19 \pm 4.97$ & $6.86 \pm 2.1$ \\
Middle dose group (E) & $2.275 \mathrm{~g} / \mathrm{kg}$ & $21.73 \pm 3.93$ & $28.70 \pm 4.45$ & $6.97 \pm 2.4$ \\
High dose group (F) & $4.550 \mathrm{~g} / \mathrm{kg}$ & $22.60 \pm 3.09$ & $29.52 \pm 2.35$ & $6.92 \pm 3.1$
\end{tabular}

Note: Compared with A group: ${ }^{\text {a }} \mathrm{P}<0.05{ }^{\mathrm{b}} \mathrm{P}<0.01$; Compared with $\mathrm{B}$ group: ${ }^{\mathrm{C}} \mathrm{P}<0.05{ }^{\mathrm{d}} \mathrm{P}<0.01$; Compared with c group: ${ }^{\mathrm{e}} \mathrm{P}<0.05{ }^{\mathrm{f}} \mathrm{P}<0.01$.

The liver index in B group compared with A group $(\mathrm{P}<0.01)$ has significant differences, the liver index in B group increased 15.11\%, which indicates that acute alcohol intake can lead to swelling of the liver, causing the liver index increased, indicating the alcohol model. By statistical analysis, $\mathrm{C}$ group compared with $\mathrm{B}$ group with significant difference $(\mathrm{P}<0.01)$, liver index of $\mathrm{C}$ group decreased by $13.32 \%$, indicating tablets in the treatment of alcoholic liver injury in mice has a very good effect; $\mathrm{D}$ group and $\mathrm{B}$ group did not show significant difference $(\mathrm{P}>0.05)$, refers to the number of mouse liver decreased by $1.93 \%$ that, the low dose group could reduce the effect on the liver index, but the effect is not obvious; $\mathrm{E}$ group and $\mathrm{B}$ group have significant difference $(\mathrm{P}<0.05)$, the liver index of mice decreased by 3.86\%, indicating the middle dose group had better effect on reducing the liver index; F group compared with $\mathrm{B}$ group is significant the difference $(\mathrm{P}<0.01)$, the liver index 
decreased by $12.54 \%$, indicating the high dose group of liver index can play a good role to reduce; $\mathrm{D}$, $\mathrm{E}$ group and $\mathrm{C}$ group compared with significant difference $(\mathrm{P}<0.01) ; \mathrm{F}$ group and $\mathrm{C}$ group no Significant differences $(\mathrm{P}>0.05)$. The flower ginseng granules in high dose group the protective effect on acute alcoholic liver injury in mice was more obvious.

Influence on ALT and AST Content in Serum of Mice of Alleviating Hangover and Protecting Liver Granules of Flower of Pueraria lobata and Ginseng Radix et Rhizoma.

Table 5. ALT/AST content $(\bar{x} \pm s$, Mi cennumbern $=10)$

\begin{tabular}{cccc}
\hline Different groups & Dose $(\mathrm{g} / \mathrm{kg})$ & ALT (U/I) & AST (U/I) \\
\hline Control group (A) & -- & $22.58 \pm 4.02^{\mathrm{d}}$ & $40.31 \pm 11.77^{\mathrm{d}}$ \\
Alcohol model group (B) & -- & $41.35 \pm 10.04^{\text {bf }}$ & $62.46 \pm 12.42^{\text {bf }}$ \\
Protecting Liver Group (C) & $0.7 \mathrm{~g} / \mathrm{kg}$ & $21.68 \pm 10.12^{\mathrm{d}}$ & $39.95 \pm 12.17^{\mathrm{d}}$ \\
Low dose group (D) & $1.1375 \mathrm{~g} / \mathrm{kg}$ & $37.82 \pm 9.89^{\text {bf }}$ & $58.63 \pm 9.57^{\text {bf }}$ \\
Middle dose group (E) & $2.275 \mathrm{~g} / \mathrm{kg}$ & $29.53 \pm 14.45^{\text {acf }}$ & $45.13 \pm 11.79^{\text {de }}$ \\
High dose group (F) & $4.550 \mathrm{~g} / \mathrm{kg}$ & $23.32 \pm 5.22^{\mathrm{d}}$ & $38.27 \pm 8.29^{\mathrm{d}}$
\end{tabular}

Note: Compared with A group: ${ }^{\mathrm{a}} \mathrm{P}<0.05{ }^{\mathrm{b}} \mathrm{P}<0.01$; Compared with $\mathrm{B}$ group: ${ }^{\mathrm{C}} \mathrm{P}<0.05{ }^{\mathrm{d}} \mathrm{P}<0.01$; Compared with $\mathrm{c}$ group: ${ }^{\mathrm{e}} \mathrm{P}<0.05{ }^{\mathrm{f}} \mathrm{P}<0.01$.

By statistical analysis, we can see that compared with group A and group B, the contents of ALT and AST in serum of B group were obviously increased $(\mathrm{P}<0.01)$, which showed that the model of alcohol liver injury in mice was successful. Comparison of the content of $\mathrm{C}$ in serum of mice in ALT, AST and B group had significant difference $(\mathrm{P}<0.01)$, were decreased by $47.57 \%$ and $36.04 \%$, indicating good reducing effect of tablets on transaminase in serum; content of $\mathrm{D}$ in serum of mice in ALT and AST compared with the B group, no significant difference $(\mathrm{P}>0.05)$, its content decreased by $8.54 \%$ and $6.13 \%$ respectively, indicating that low dose group can decrease the content of serum transaminase, but the effect is not obvious; the content of ALT in serum of mice in E group and B group were significantly different $(\mathrm{P}<0.05)$. The content was decreased by $43.60 \%$ and $38.73 \%$, respectively. The high dose group has significant curative effect on reducing the transaminase content in serum. D group and $C$ group have significant difference $(P<0.01)$, E group and $C$ group had significant difference $(\mathrm{P}<0.05)$, F group compared with no significant difference $(\mathrm{P}>0.05)$, so we can see that the Ge flower ginseng granules of low medium and high dose group for ALT and AST in acute alcoholic liver mice serum all can reduce the effect of the high dose group has the most obvious effect.

\section{Conclusion}

The result showed that alleviating hangover and protecting liver granules of flower of Pueraria lobata and Ginseng Radix et Rhizoma has a protective effect on acute alcoholic liver injury, the effect of high dose group was the best, to good effect on reducing group transaminase levels in serum and liver index of mice. As the incidence of alcoholic liver disease increases year by year, it is of great market prospect to study and develop new anti-liver protective drugs, and hope to provide a reliable experimental basis for further research and development.

\section{Acknowledgements}

The paper is the periodical result of the Youth Foundation Project of Agriculture Science and Technology College (Grant No. 202 of 2015). 


\section{References}

[1] Liang Gai, Zhan Li, Wang Hui. et al. Protection and Mechanism of Panax Ginseng and Hovenia Dulcis Thunb on Acute Alcoholism Mice [J]. Journal of New Medicine, 2006, 16(2): 82-83+89.

[2] Yin Jiale, Li Xin, Zhang Shixia, Zhang Hongquan. Protective effect of $\mathrm{C}_{21}$ steroidal ester saponi in of cynanchum auricul at umroyle exwight on acute $\mathrm{CCl}$ - induced liver injury in mice [J]. Anhui Medical and Pharmaceutical Journal, 2007, 11(3): 198-200.

[3] Qi Huihui, Song Jia, Chen Yuexiang. Development of a mouse model of alcohol-induced acute liver injury [J]. World Chinese Journal of Digestology, 2012, 20(9): 759-763.

[4] Dai Yulin, Zheng Fei, Huang Xin, Li Xiaoyu, Yue Hao, Liu Shuying. Effect of Compatibility of Ginseng Radix et Rhizoma and Flower of on Pueraria lobata on Alleviating Hangover and Protecting Liver [J]. Chinese Journal of Experimental Traditional Medical Formulae, 2016, 22(4): 45-49. 